\title{
Use of Language Tests when Identifying Specific Language Impairment in Primary Health Care
}

\author{
Sinikka Hannus ${ }^{a}$ d Timo Kauppila $^{a}$ d Janne Pitkäniemi ${ }^{b}$ Kaisa Launonen ${ }^{c}$ \\ ${ }^{a}$ Network of Academic Health Centres, Department of General Practice and Primary Health Care, HUS, \\ ${ }^{b}$ Hjelt-Institute, Department of Public Health, and ' Institute of Behavioural Sciences/Logopedics, University of \\ Helsinki, Helsinki, and ${ }^{d}$ Vantaa Social Welfare and Health Care, Vantaa, Finland
}

\section{Key Words}

Assessment · Communication skills · Developmental disorders · Diagnosis · International classification of impairments · Linguistic skills · Specific language impairment (SLI)

\begin{abstract}
Objective: To evaluate the ability of language tests to identify children with specific language impairment (SLI) in primary health care. All the language tests presently in clinical use in Finland were applied. Method: All the children with SLI living in one city in Finland constituted the cohort. Test scores were collected from 83 subjects drawn from a birth cohort of 4,553 children. Finally 31 case-control pairs were studied. All SLI diagnoses were set in secondary health care. Test scores of 14 language tests were examined that, together with subtests, included 39 different tasks. Results: Out of 39 performed tests, the difference in test scores between children with SLI and their matched controls was statistically significant in 26 tests. A group of six tests had good sensitivity and moderate specificity for SLI diagnosis and they correctly classified children with SLI to either F80.1 or F80.2 diagnosis category. Conclusion: The results suggest that most of the language tests in Finnish identify children with SLI and, furthermore, that these tests identify language deficits that are consistent with those found in other studies. More studies with larger age-matched populations are needed.
\end{abstract}

Copyright ๑ 2013 S. Karger AG, Basel

\section{KARGER}

E-Mail karger@karger.com www.karger.com/fpl
(C) 2013 S. Karger AG, Basel 1021-7762/13/0651-0040\$38.00/0

Karger

0 pen access

This is an Open Access article licensed under the terms of the Creative Commons Attribution-NonCommercial 3.0 Unported license (CC BY-NC) (www.karger.com/OA-license), applicable to the online version of the article only. Distribution permitted for non-commercial purposes only.

\section{Introduction}

Due to the considerable morbidity of developmental language disorders $[1,2]$ and the potential cost to society related to these disorders, evidence-based practice in diagnosing children with developmental language disorders has been increasingly emphasized during recent years $[3,4]$. Accurate assessment and reliable diagnostic tools are essential in language disorders and they sustain the clinicians' confidence in diagnoses. In order to achieve these targets further studies assessing language impairment are needed.

The International Classification of Diseases (ICD-10) [5] provides two diagnoses to distinguish the subgroups of specific language impairment (SLI): diagnosis F80.1 - 'a specific developmental disorder in which the child's ability to use expressive spoken language is markedly below the appropriate level for its mental age, but in which language comprehension is within the normal limits', and diagnosis F80.2 - 'a specific developmental disorder in which the child's understanding of language is below the appropriate level for its mental age. In virtually all cases expressive language will also be markedly affected and abnormalities in word-sound production are common.' The diagnostic criteria of SLI, or language delay on the whole, include test scores [6]. However, they have not achieved international acceptance of their normative scores, validity or clinical markers either by clinicians or researchers

Sinikka Hannus

Myyrmäen terveysasema Jönsaksentie 4

FI-01600 Vantaa (Finland)

E-Mail sinikka.hannus@helsinki.fi 
$[4,7-10]$. Diagnosis of SLI is not solely based on test scores [11]; however, their normative values are clinically important in the daily work of physicians who specify the diagnosis, as well as of speech and language therapists (SLTs) who administer and score the tests in both primary and secondary health care. Language tests are also applied in the follow-up of the rehabilitation.

The questions of the possible universal characteristics of language learning in general and, more specifically, the specific traits of SLI in different languages, require studies in different language environments [10, 12-15]. Most of the test procedures used to identify and describe subgroups of language impairments are standardized either in English or in the language of one country only [4, 15, 16]. Smaller populations with their own languages, such as Finnish, may only have indicative norms. These norms are usually created on the basis of scarce or insufficient scientific data or clinical trials with a small and selected number of participants [16]. Furthermore, the performance of different available tests has not been compared in populations of children with SLI. Thus, we have limited knowledge about these tests in Finland as well as in other countries [17].

\section{General Path of Assessment of Children with}

Developmental Language Disorders in Finland

The first step in the path of intervention for a child with a suspected delay in speech and language development in Finland is usually taken at the child welfare clinic. At these clinics child welfare nurses use screening instruments that SLTs have developed for their use. There are separate instruments for each age group. When a child is identified as at risk in the age-specific screening procedure, parents are advised to contact a SLT. As the speech and language therapy services in primary health care in Finland are free of charge, practically all parents contact the SLT and an assessment is carried out to determine which services are needed. In addition to formal testing, observations of the child and parent interviews form an essential part of the assessment of the child's language abilities. However, only the test scores can be considered and compared to peers of different ages. The final step is referral to a secondary health care centre to make the diagnosis. According to Finnish law, a physician is always responsible for making the diagnosis.

The primary aim of this study was to evaluate the Finnish language tests and international language tests translated into Finnish that are used on a daily basis in primary health care to assess children's speech and language abilities. Accordingly, the main questions were: (1) Is
Table 1. Participants of the study

\begin{tabular}{lccc}
\hline & Boys & Girls & Total \\
\hline Type of diagnosis & & & \\
$\quad$ F80.1 & 22 & 6 & 28 \\
F80.2 & 16 & 2 & 18 \\
$\quad$ Total & 38 & 8 & 46 \\
No SLI diagnosis (controls) & 30 & 7 & 37 \\
Total number of children & 68 & 15 & 83 \\
Number of matched pairs & & & \\
$\quad$ F80.1 & 17 & 4 & 21 \\
F80.2 & 9 & 1 & 10 \\
Total & 26 & 5 & 31 \\
\hline
\end{tabular}

Number of diagnoses F80.1 and F80.2 and number of control children, numbers of boys and girls. Number of matched pairs in F80.1 and F80.2, numbers of boys and girls.

there a difference in language test scores between children with SLI and their matched controls? (2) Do the language test scores discriminate between the two SLI diagnoses, F80.1 and F80.2?

\section{Method}

\section{Subjects and Measures}

Data were collected from all children born in 1998 and 1999 who were diagnosed in secondary health care to have SLI (ICD-10 diagnoses F80.1 or F80.2) living in the city of Vantaa, Finland. The size of this birth cohort was 4,553 children in January 2006 [18]. The data of children are the same as in the larger research project 'SLI in a Finnish Town' [19] studying also the aetiology and the prognosis of SLI. After meeting the study criteria (Finnish as mother tongue, normal intellectual ability, normal hearing, agreement to participate in this study, diagnosis F80.1 or F80.2), 46 children with SLI presented diagnoses F80.1 $(\mathrm{n}=28,61 \%)$ and F80.2 ( $\mathrm{n}=18,39 \%$, table 1$)$. The flowchart of the children's involvement in the study is given in figure 1 .

In the research project 'SLI in a Finnish Town' [19] control children were matched to the children with SLI, based on gender, month of birth ( \pm 1 month) and the area of the town they lived in. However, in this study the matched pairs were not tested at the same age. Finally, in this study, 31 matched pairs were compared. The children with SLI and their controls were born in 1998 (68\%) or 1999 (32\%). None of the control children had any major handicap or identifiable developmental handicap when screened at a child welfare clinic. Because articulation errors of /s/ and /r/ are common at this age in Finnish children, those were not used as exclusion criteria for the control group.

Collecting the data of test scores started in January 2005 and ended in April 2006. The age of the case-control pair was not the same during the test performance because the children joined the study at different ages and testing arrangements for each child could not be synchronized. A 6-month interval between test per- 
Fig. 1. Flowchart of child involvement.

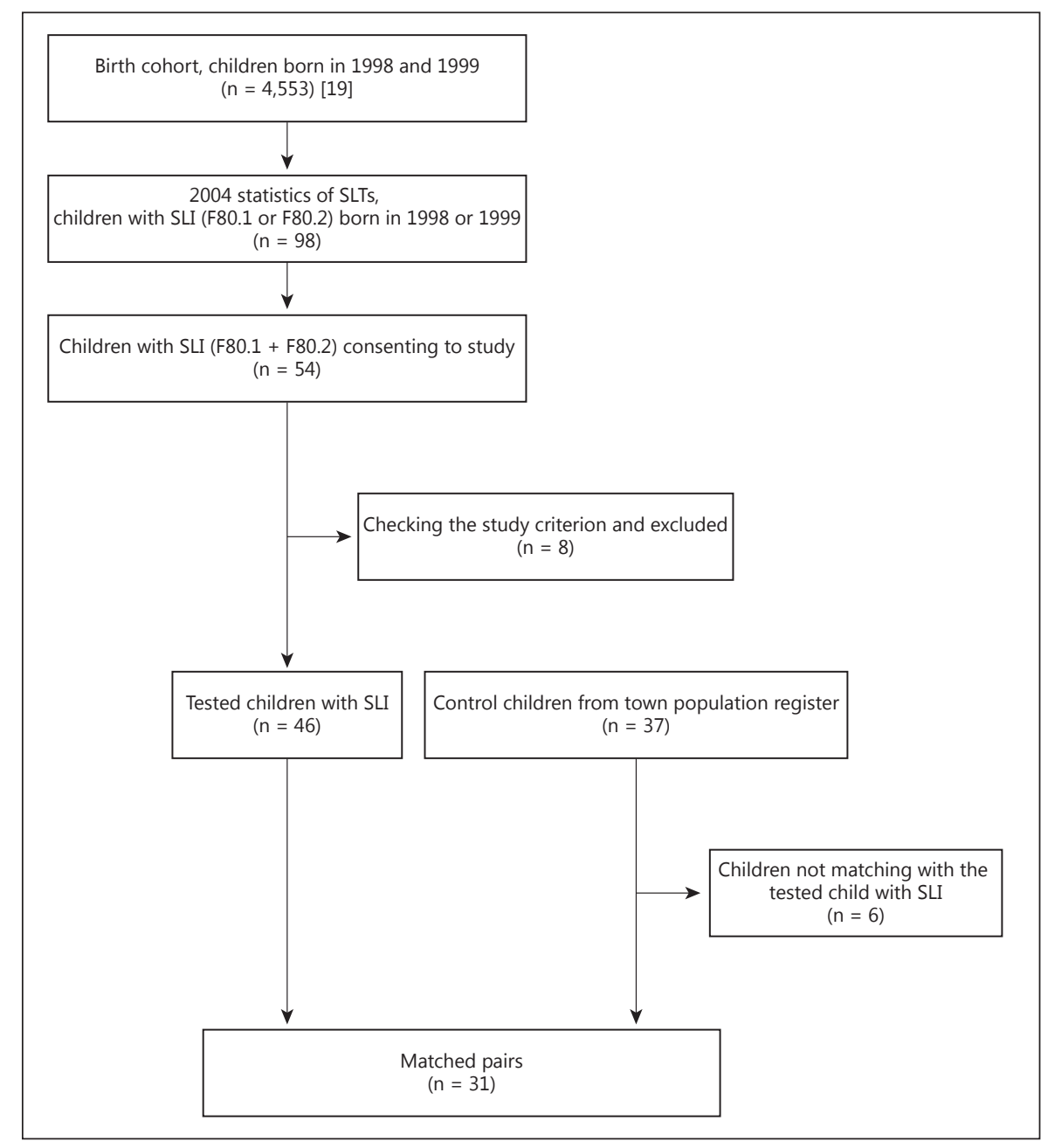

formances is recommended, and, in some cases the earlier test scores were utilized. These two reasons caused the age range of the children to vary from 4 years and 3 months to 8 years and 2 months (mean 6 years and 8 months, $\mathrm{SD}=8.2$ months). Altogether 32 SLTs assessed language abilities of the children in the clinics of the SLTs in primary health care, at the day care facility, the child's school or at the private clinic of the SLT. Test scores that were used when children were diagnosed in secondary health care were not available in primary health care, and, thus, were not available in this study either. Blinding the diagnostic group was not possible in this study as the same SLTs administered the testing and rehabilitation of children with SLI.

Fourteen different assessment methods or tests were used. Together with their subtests they included 39 different tasks (table 2). Clinical experience, together with the knowledge from international studies, has developed these tests into widely used clinical tools.

\section{Data Analysis}

The data of matched pairs were analysed by calculating the difference in the raw test scores for each matched pair of children, as well as mean scores, corresponding standard deviations and the standardized effect size and 95\% confidence intervals (CI). Since, in the calculation of $\mathrm{p}$ values, we adjusted for the difference in age at testing between SLI cases and controls, and controlled for multiple comparisons (39 tested items), we make conclusions concerning statistical significance using these $p$ values. In calculating the $p$ values the false discovery rate [35] procedure was applied to avoid reporting false positive findings. Linear discriminant analysis was performed to discriminate between the test scores of SLI children with either an F80.1 or F80.2 diagnosis. Statistical package SPSS 15 was used to compute the statistical analysis [36].

\section{Results}

\section{Difference in Test Scores between Children with SLI and Control Children}

After testing the differences in age when the test was given, the difference in test scores between the matched pairs $(\mathrm{n}=31)$ was statistically significant $(\mathrm{p}<0.01)$ in 26 tests (table 2 ). These 26 tests formed an entity of vocabu- 


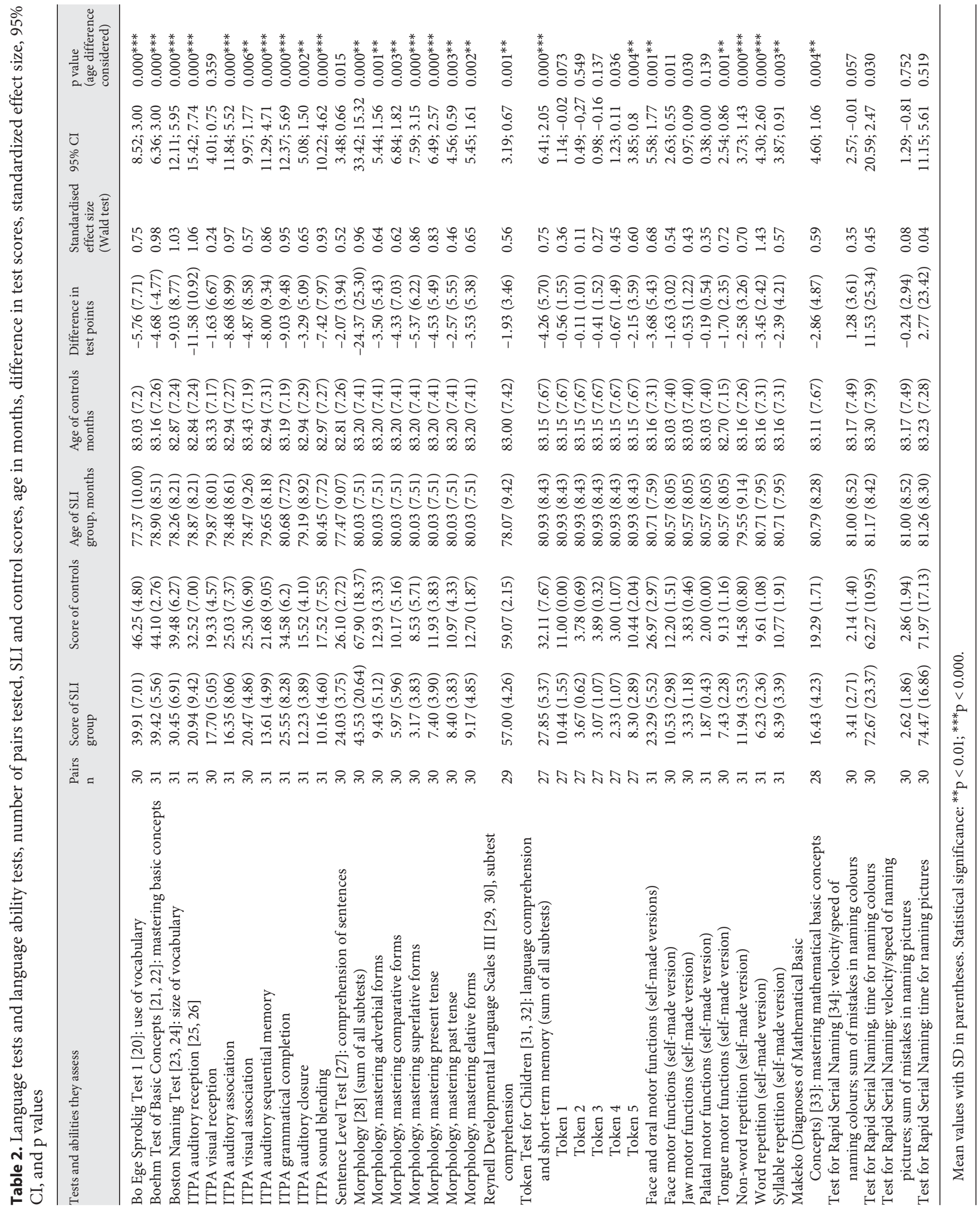


Table 3. Classification results from the discriminant analysis (F80.1 and F80.2)

\begin{tabular}{lccc}
\hline \multirow{2}{*}{$\begin{array}{l}\text { Observed } \\
\text { diagnoses }\end{array}$} & \multicolumn{2}{c}{ Predicted group diagnosis } & \multirow{2}{*}{ Total } \\
\cline { 2 - 3 } & F80.1 & F80.2 & \\
\hline F80.1, n & 25 & 3 & 28 \\
F80.2, n & 4 & 12 & 16 \\
F80.1, \% & 89.3 & 10.7 & 100 \\
F80.2, \% & 25.0 & 75.0 & 100 \\
\hline
\end{tabular}

Accuracy $84.1 \%$ (percentage of original grouped cases that were correctly classified).

lary and concepts and their use, comprehension of sentences, auditory skills, morphological skills and repetition and motor functions of the face and oral production (table 2). In 13 tests the difference in scores between the matched pairs was not statistically significant. The tests included visual tests, motor functions of the jaw, palate and face, sentence comprehension and rapid serial naming.

\section{Difference in Test Scores between Children with}

Diagnoses F80.1 and F80.2

Discriminant analysis revealed a group of six tests to have good sensitivity $(89.3 \%, 95 \%$ CI: $71.8-97.7 \%)$ and moderate specificity (75\%, 95\% CI: 47.6-92.7\%) (table 3) when diagnosing SLI. This group of six tests consisted of a sentence level test of speech comprehension, three morphological tests addressing the mastering of present tense, superlative and comparative forms, respectively, a test of word repetition and, finally, an assessment of the motor function of the palate; $84.1 \%$ of the children with diagnoses F80.1 or F80.2 were classified correctly.

\section{Discussion}

The aim of this study was to determine the ability of all the language tests in clinical use in Finland to differentiate the diagnosed children with SLI from their controls. In this study 26 tests differentiated children with SLI from matched control children at the group level. Furthermore, the language deficits of children with SLI in Finnish that were found in this study are consistent with those found in international studies $[7,8,16,17]$. On a local basis, the result increases the clinicians' confidence, both physicians' and SLTs', in language tests even in the case of smaller populations with their own languages, such as Finnish.

\section{Difference in Test Scores between Children with SLI and Their Controls}

Among the language tests that discriminate children with SLI from their controls were tests that have been translated into Finnish and have standard scores, self-created tasks as well as tests that only have norms. Though clinicians can rely on these tools, in the future it is worth carrying out standardizing studies on the self-created tests and tests with norms. Among the 13 tests that failed to discriminate children with SLI from their controls there were both self-created tasks and tests that only have norms and standardized tests. This result, especially concerning standardized tests, needs further study.

Children with SLI typically show more than one deficit. Researchers have tried to find 'clinical markers' of SLI and these studies have been carried out on children of different ages and, furthermore, in different languages $[7,8$, 10]. Studies to date suggest non-word repetition and past tense marking to be worth assessing when identifying children with SLI. Furthermore, verb morphology may also be of interest based on a number of studies in various languages $[7,37]$ as well as auditory processing [38]. The results of this study support the use of these clinical markers when identifying SLI in primary health care, and they also provide further evidence to support their inclusion as universal characteristics of language difficulties. The limited amount of data and non-equal scores in different tests do not allow further conclusions, either from scores at different ages or threshold for the diagnosis in each test.

\section{Difference in Test Scores between Children with \\ Diagnoses F80.1 and F80.2}

In the present study SLI was defined using ICD-10 diagnoses including both expressive and receptive problems (F80.1 and F80.2) that are supposed to have different outcomes. Among these test performances there are inconsistent results that support the international discussion of the overlapping of these two diagnoses and the difficulties in defining their borders [1]. In the earlier Finnish study [14] only $37 \%$ of the control children performed age-appropriately in all verbal tasks, most of which were used in this study. Many factors may contribute to the actual performance of a child, e.g. lack of concentration as well as the effects of fatigue when performing many tests. The results of our data suggest that a reduction in the amount of language tests in clinical use would be warranted. 
A representative set of language tests seems to be difficult to find in spite of the international studies that have been carried out over many years. In a Finnish study SLTs reported that they use on average 14 different tests currently, the range being 1-33 [39]. This number also included various unspecified, self-created and selfadapted assessment procedures. Despite the large selection of tests, SLTs wanted new and more applicable tests. Thus, national multicentre studies of the usefulness of the current tests, as well as studies for the new tests, are needed.

\section{Strengths and Weaknesses of the Study}

The main strength of the study is that it was carried out in the fourth largest town in Finland, and thus, includes a representative sample of SLI because all the children born in 1998 and 1999 who were diagnosed as having SLI living in this town were included in this study. A further strength is that these data include all the tests in clinical use. This study is part of a larger research project, 'SLI in a Finnish Town' [19].

The main weakness of this study is that the ages when tests were administered were not the same in case-control pairs. However, the statistical methods employed take this difference into account. In the statistical analysis of the data we focused on assessing exact $p$ values due to the small sample size. Because matched case-control design is the most efficient study design when outcomes are relatively rare [40], e.g. SLI, we adjusted the possible additional confounding effect of the age when language tests were performed with the false discovery rate procedure. Despite the limitations created by the small sample size, factors separating the diagnosed groups F80.1 and F80.2 using linear discriminant analysis (false discovery rate) were explored. In order to keep overall significance, multiple testing corrections were performed to reduce the possibility of reporting false positive language tests.

Furthermore, parents were asked to fill in many forms as part of various subprojects in this research project. This, in turn, may have resulted in low commitment to the research project; only about half of the identified children's parents agreed to participate in the study. Also, the case-control setting diminished the number of children. When administering the tests in the study protocol we were careful to cause minimal disturbance to the children. Rehabilitation of children with SLI continued at the same time and proceeding with rehabilitation was ethically more valuable than administering the tests. The children's rehabilitation, which took place at the same time as testing, the large number of tests and the long time necessary for testing did not allow a blind testing procedure.

This study is an initial, phase I-type [41] attempt to determine whether individuals with and without the condition (e.g. SLI) differ at a group level. Although this study does not fulfil all the requirements of Standards for Reporting of Diagnostic Accuracy [42], it deserves being reported as a preliminary result. Significantly, this is the largest available Finnish-speaking population of SLI children whose diagnosis and testing are made with the relevant methodology in the area of the Finnish language. We hope that the present research encourages other workers to continue our search for gold standards for diagnosing SLI, with better resources and larger population samples and by following the checklist of the Standards for Reporting of Diagnostic Accuracy [43].

\section{Conclusions}

The result of this study supports the existence of internationally identified clinical markers of SLI and supports the use of 26 tests as tools for clinical use in primary health care. More studies with larger age-matched populations are needed to find the diagnostic thresholds of each test as well as their validity. Furthermore, the challenge for future studies is to decrease the range of tests, also guaranteeing the best performance of each child.

\section{Acknowledgements}

This study was supported by the Association of Avohoidon tutkimussäätiö (Foundation of Outpatient Care).

Contributors: This study is part of the research project 'SLI in a Finnish Town' studying the aetiology, status and prognosis of SLI. Public health nurses Minna Haanpää and Aino Rista acted as research nurses. Paediatrician Leena Isotalo and SLT Pia Isoaho had useful discussions about the nature of SLI with the authors.

\section{Disclosure Statement}

The authors declare that they have no competing interest. 


\section{References}

1 Law J, Boyle J, Harris F, Harkness A, Nye C: Screening for speech and language delay: a systematic review of the literature. Health Technol Assess 1998;2:1-184.

$>2$ Hannus S, Kauppila T, Launonen K: Increasing prevalence of SLI in a Finnish town in 1989-1999. Int J Lang Commun Disord 2009; 44:79-97.

3 Reilly S: The move to evidence-based practice within speech pathology; in Reilly S, Douglas J, Oates J (eds): Evidence Based Practice in Speech Pathology. London, Whurr, 2004, pp 3-17.

-4 Spaulding T, Plante E, Farinella K: Eligibility criteria for language impairment: is the low end of normal always appropriate? Lang Speech Hear Serv Sch 2006;37:61-72.

5 World Health Organisation: International Classification of Diseases (ICD-10). http:// www.who.int

6 Eadie P: The evidence base for the diagnosis of developmental language disorders: research to clinical practice; in Reilly S, Douglas J, Oates J (eds): Evidence Based Practice in Speech Pathology. London, Whurr, 2004, pp 185-205.

7 Conti-Ramsden G: Processing and linguistic markers in young children with specific language impairment (SLI). J Speech Lang Hear Res 2003;46:1029-1037.

-8 Stokes SF, Wong AM, Fletcher P, Leonard LB: Nonword repetition and sentence repetition as clinical markers of specific language impairment: the case of Cantonese. J Speech Lang Hear Res 2006;49:219-236.

$>9$ Slott M, Vach W, Bleses D: Evaluation of methods used to assess language development of 3- to 4-year-old Danish children. Logoped Phoniatr Vocol 2008;33:190-207.

10 Savinainen-Makkonen T: Word initial consonant omissions - a developmental process in children learning Finnish. First Lang 2000;20: 161-185.

11 Specific Language Impairment (SLI): Current Care Summary. 27.4.2010. Working group appointed by the Finnish Medical Society Duodecim, the Finnish Association of Phoniatrics and Finnish Association of Paediatric Neurology. http://www.kaypahoito.fi/web/ $\mathrm{kh} /$ suositukset/naytaartikkeli/tunnus/ ccs00076.

12 Kunnari S: Characteristics of Early Lexical and Phonological Development in Children Acquiring Finnish; PhD thesis, Oulu, 2000. Acta Universitatis Ouluensis B 34.

13 Bishop D: Uncommon Understanding: Development and Disorders of Language Comprehension in Children. Hove, Psychology Press, 2004

14 Asikainen M: Diagnosing Specific Language Impairment; MD thesis, Tampere, 2005. Acta Universitatis Tamperensis 1113. Tampere, Tampere University Press, 2005.
15 Bortolini U, Arfe B, Caselli CM, Degasperi L, Deevy P, Leonard LB: Clinical markers for specific language impairment in Italian: the contribution of clitics and non-word repetition. Int J Lang Commun Disord 2006;41: 695-712.

16 van Weerdenburg M, Verhoeven L, van Balkom H: Towards a typology of specific language impairment. J Child Psychol Psychiatry 2006;47:176-189.

17 Kasper J, Kreis J, Scheibler F, Möller D, Skipka G, Lange S, von dem Knesebeck O: Population-based screening of children for specific speech and language impairment in Germany: a systematic review. Folia Phoniatr Logop 2011;63:247-263.

18 Vantaan kaupunki, Tilasto ja tutkimus, B9: 2006. Vantaan väestö 2005/2006 (Town of Vantaa, Research and Statistics, B9: 2006) http://www.vantaa.fi/tilastot

19 Isoaho P: Specific Language Impairment (SLI) and Its Development in the Early School Years (in Finnish); PhD thesis, Helsinki, 2012.

20 Ege B: Ringstedmaterialet. Sproglig Test 1. Herning, Special-paedagogisk forlag a/s, 1984 (Finnish version speech and language therapists of Pirkanmaa, test group Early Learning Oy, Helsinki, 1984).

21 Boehm AE: Boehm Test of Basic Concepts: Manual, revised. Orlando, Psychological Corporation, 1986.

22 Heimo H: Boehmin peruskäsitetesti, suomalaisen laitoksen käsikirja (Boehm Test of Basic Concepts, Handbook of Finnish Version). Helsinki, Psykologien Kustannus Oy, 1993.

23 Kaplan C, Goodglass H, Weintraub S: Boston Naming Test. Boston, Boston Aphasia Research Centre, Boston University, 1976.

24 Laine M, Koivuselkä-Sallinen P, Hänninen R, Niemi J: Bostonin nimentätesti (Boston Naming Test). Helsinki, Psykologien Kustannus, 1997.

25 Kirk S, McCarthy J, Kirk W: Illinois Test of Psycholinguistic Abilities: Examiner's Manual, revised ed. Urbana, University of Illinois, 1968.

26 Kuusinen J, Blåfield L: Psychometric characteristics of the Finnish ITPA. Reports of the Institute for Educational Research 241/1974. Jyväskylä, University of Jyväskylä, 1974.

27 Korpilahti P: A Sentence Level Test for Speech Understanding(in Finnish). Helsinki, Language and Communication Care, 1996.

28 Lyytinen P: The Morphology Test: A Measure of the Mastery of Children's Inflectional Forms (in Finnish). Reports from the Department of Psychology 298. Jyväskylä, University of Jyväskylä, 1988.
29 Edwards S, Fletcher P, Garman M, Hughes A, Lettes C, Sinka I: Reynell Developmental Language Scales III: Manual, ed 3. Windsor, NFER-Nelson, 1997.

30 Kortesmaa M, Heimonen K, Merikoski H, Warma M-L, Varpela V: Reynell Developmental Language Scales III - RLDS III (in Finnish). Helsinki, Psykologien Kustannus, 2001.

31 DiSimoni F: The Token Test for Children. Chicago, Riverside Publishing, 1978.

32 Korkman M: NEPSU, The Neuropsychological Test Battery for Children. Helsinki, Psykologien Kustannus Oy, 1988.

33 Ikäheimo H: The Diagnoses of Mathematical Basic Concepts (in Finnish). Helsinki, Oy Opperi Ab, 2002.

34 Ahonen T, Tuovinen S, Leppäsaari T: Test for Rapid Serial Naming (in Finnish). Publications of Haukkaranta School, Research reports. Jyväskylä, Haukkarannan koulu, 1999.

35 Benjamini Y, Hochberg Y: Controlling the false discovery rate: a practical and powerful approach to multiple testing. J R Stat Soc Series B (Methodology) 1995;57:289-300.

36 SPSS 15 Command Syntax Reference 2006. Chicago, SPSS Incorporation, 2006.

37 Kunnari S, Savinainen-Makkonen T, Leonard LB, Mäkinen L, Tolonen AK, Luotonen M, Leinonen E: Children with specific language impairment in Finnish: the use of tense and agreement inflections. J Child Lang 2011;38: 999-1027.

-38 Huber M, Telser S, Falk M, Bohm A, Hackenberg B, Schwitzer J, Hinterhuber H: Information transmission defect identified and localized in language learning impaired children by means of electrophysiology. Cortex 2005; 41:464-470.

39 Huttunen K, Paavola L, Suvanto A: Tests and assessment methods currently used and new ones desired by Finnish speech and language therapists; in Klippi A, Launonen K (eds): Research in Logopedics: Speech and Language Therapy in Finland. Clevedon, Multilingual Matters, MPG Books Ltd, 2008, pp 19-32.

40 Hartung DM, Touchette D: Overview of clinical research design. Am J Health Syst Pharm 2009;66:398-408.

41 Sackett DL, Haynes RB: The architecture of diagnostic research. BMJ 2002;324:539-541.

42 Klee T: Consideration for appraising diagnostic studies of communication disorders. Considerations for appraising studies. Evid Based Commun Assess Intervent 2008. DOI: 10.1080/17489530801927757.

43 Whiting P, Rutjes AWS, Reitsma JB, Bossuyt PMM, Kleijnen J: The development of QUADAS: a tool for the quality assessment of studies of diagnostic accuracy included in systematic reviews. BMC Med Res Methodol 2003;3: 25. 